\title{
BMJ Open Impact of drug consumption rooms on risk practices and access to care in people who inject drugs in France: the COSINUS prospective cohort study protocol
}

\author{
Marc Auriacombe, , ,2,3,4 Perrine Roux, ${ }^{5,6}$ Laélia Briand Madrid, ${ }^{5,6}$ \\ Sébastien Kirchherr, ${ }^{7}$ Charlotte Kervran, ${ }^{1,2}$ Carole Chauvin, ${ }^{8}$ Marie Gutowski, ${ }^{5,6}$ \\ Cécile Denis, ${ }^{2,3}$ Maria Patrizia Carrieri, ${ }^{5,6}$ Laurence Lalanne, ${ }^{9,10}$ \\ Marie Jauffret-Roustide, ${ }^{8}$ and the Cosinus study group.
}

To cite: Auriacombe M, Roux P, Briand Madrid L, et al. Impact of drug consumption rooms on risk practices and access to care in people who inject drugs in France: the COSINUS prospective cohort study protocol. BMJ Open 2019;9:e023683. doi:10.1136/ bmjopen-2018-023683

MA, PR, LL and MJ-R contributed equally.

Received 18 April 2018 Revised 27 December 2018 Accepted 4 January 2019
Check for updates

(C) Author(s) (or their employer(s)) 2019. Re-use permitted under CC BY-NC. No commercial re-use. See rights and permissions. Published by BMJ.

For numbered affiliations see end of article.

Correspondence to Dr Perrine Roux; perrine.roux@inserm.fr

\section{ABSTRACT}

Introduction The high prevalence of hepatitis $C$ and the persistence of HIV and hepatitis $\mathrm{C}$ virus (HCV) risk practices in people who inject drugs (PWID) in France underlines the need for innovative prevention interventions. The main objective of this article is to describe the design of the COSINUS cohort study and outline the issues it will explore to evaluate the impact of drug consumption rooms (DCR) on PWID outcomes. Secondary objectives are to assess how DCR (a) influence other drug-related practices, such as the transition from intravenous to less risky modes of use, (b) reduce drug use frequency/quantity, (c) increase access to treatment for addiction and comorbidities (infectious, psychiatric and other), (d) improve social conditions and (e) reduce levels of violence experienced and drug-related offences. COSINUS will also give us the opportunity to investigate the impact of other harm reduction tools in France and their combined effect with DCR on reducing HIV-HCV risk practices. Furthermore, we will be better able to identify PWID needs.

Methods and analysis Enrollment in this prospective multi-site cohort study started in June 2016. Overall, 680 PWID in four different cities (Bordeaux, Marseilles, Paris and Strasbourg) will be enrolled and followed up for 12 months through face-to-face structured interviews administered by trained staff to all eligible participants at baseline (M0), 3 month (M3), 6 month (M6) and 12 month (M12) follow-up visits. These interviews gather data on socio-demographic characteristics, past and current drug and alcohol consumption, drug-use related practices, access to care and social services, experience of violence (as victims), offences, other psychosocial issues and perception and needs about harm reduction interventions and services. Longitudinal data analysis will use a mixed logistic model to assess the impact of individual and structural factors, including DCR attendance and exposure to other harm reduction services, on the main outcome (HIV-HCV risk practices).

Ethics and dissemination This study was reviewed and approved by the institutional review board of the French Institute of Medical Research and Health (opinion number:

\section{Strengths and limitations of this study}

- This is the first multi-site harm reduction focused cohort of practices in people who inject drugs (PWID) conducted in France.

- The study's findings will help to assess the impact of drug consumption rooms and other harm reduction services on HIV and hepatitis C virus risk practices in PWID.

- The findings will also assess the needs of PWID in France by providing a greater understanding of their social conditions, access to prevention and treatment services.

- Non-French-speaking PWID are excluded from the cohort so their specific needs are not assessed; they may represent up to $20 \%$ of people who attend harm reduction facilities in some sites.

14-166). The findings of this cohort study will help to assess the impact of DCR on HIV-HCV risk practices and other psycho-social outcomes and trajectories. Moreover, they will enable health authorities to shape health and harm reduction policies according to PWID needs. Finally, they will also help to improve current harm reduction and therapeutic interventions and to create novel ones.

\section{INTRODUCTION}

\section{Rationale}

In France, as elsewhere, people who inject drugs (PWID) faced a dramatic HIV epidemic in the 1990s. In response, the French government's harm reduction policy, which first developed programmes for access to sterile injection material in 1987, extended access in 1994 to include syringe vending machines and the sale of readyto-use injection kits (Steribox) in community pharmacies, ${ }^{1}$ as well as new state-funded 
needle exchange programmes (NEP). ${ }^{2}$ These public health initiatives were concomitant with opiate maintenance treatment (OMT) programmes with methadone (available since 1994) and buprenorphine (available since 1995$)^{34}$ and HAART for HIV-infected individuals. ${ }^{5}$ HIV prevalence in PWID dramatically decreased from $40 \%$ to $20 \%$ in 14 years from 1988 to $2002,{ }^{2}{ }^{6}$ with a prevalence in 2011 of $10 \%{ }^{7}$ An estimated $77 \%$ to $85 \%$ of opioid-dependent individuals in France are currently treated with OMT. ${ }^{7}$

Despite this progress, and just as in many countries where OMT and NEP are available, ${ }^{8}$ the impact of this harm reduction policy on the hepatitis $\mathrm{C}$ virus (HCV) epidemic in France has not been as great as that for HIV. ${ }^{29-12}$ This is because this policy was adopted when HCV prevalence was already too high to be rapidly controlled. In 2011, HCV infection prevalence in the country was $64 \%$ among many PWID. ${ }^{7}$ HCV incidence was also very high, between $11 \%$ and $22 \%,{ }^{13}$ compared with neighbouring countries such as the Netherlands. ${ }^{14}$ The delay in implementing an efficient harm reduction policy may explain the persistent high national prevalence of HCV in PWID today. ${ }^{15}$ Besides HCV and HIV infections, numerous other physical problems can result from injecting drug use, including soft tissue infections, ${ }^{16}{ }^{17}$ cardiovascular and pulmonary complications, ${ }^{18}$ and bacterial and fungal infections. ${ }^{19}$ In addition, research on existing drug consumption rooms (DCR) showed that they improve access to primary healthcare and improve safer injection conditions. ${ }^{20}$ By attracting the most marginalised PWID, ${ }^{21}$ they also reduce the level of public injection and so the number of used syringes has dropped in public spaces. ${ }^{22}$ Finally, it has also been shown that DCR are effective in reducing fatal overdoses. ${ }^{23}$

Despite the French health authorities' reluctance to open DCR for many years, mostly because of the country's persistent repressive policy towards drug use and general negative public opinion, ${ }^{24}$ their success in other countries encouraged the French government to reconsider DCR as a possible additional harm reduction (HR) tool. Two DCR, in Paris and Strasbourg, were opened in 2016 as part of a 6 year experiment granted on the condition that the health and social impact of the facilities would be rigorously evaluated. These two DCR accept all PWID 18 years or older and provide the following services: the possibility to administer drugs by injection (or inhalation in some cases, only for PWID), access to social, medical and psychiatric consultations, the provision of sterile equipment, the collection and disposal of used injection equipment, primary care, harm reduction counselling and HCV, hepatitis B virus (HBV) and HIV testing. In this perspective, the COSINUS cohort (COhort to identify Structural and INdividual factors associated with drug Use) was set up in 2016 to prospectively evaluate the impact of DCR on the reduction of risk-taking behaviours in PWID.

The main objective of this article is to describe the design of the COSINUS cohort study and outline which issues it will explore to evaluate the impact of the DCR on PWID outcomes.

\section{Research objectives and hypothesis}

The main objective of COSINUS is to evaluate the impact of regular DCR use on HIV and HCV risk practices. The hypothesis is that PWID with regular access to DCR have fewer practices at risk of HCV and HIV transmission than PWID with no access. It will also investigate the impact of regular DCR use on access to care. Furthermore, data from COSINUS will be used to study the impact of other individual (eg, age, gender, ethnicity, housing) and structural (eg, exposure to social services, harm reduction services including education about safer injection $)^{25}$ factors on several outcomes (other risk practices, criminality, current drug use, negative life events, etc.). More specifically, it will help provide a greater understanding of the combined effect of different harm reduction services on PWID health and risk practices.

\section{METHODS AND ANALYSIS \\ Study design}

This prospective, multi-center cohort study, which started in June 2016, will enrol a total of 680 PWID by October 2017 in four different French cities with different geographical and health characteristics (Bordeaux, Marseilles, Paris and Strasbourg). The study design and data collection tools were partly inspired by an evaluation of the Vancouver Downtown Eastside DCR (Insite) ${ }^{26}$ and the Vancouver Injection Drug User Study. ${ }^{27}$ Individual follow-up will last 12 months. PWID in the DCR in Paris and Strasbourg constitute the 'treatment' group (hereafter 'DCR-exposed'), while PWID already enrolled in harm reduction programmes constitute the 'control' group (hereafter 'DCR-unexposed'). These four cities were chosen because they were all candidates for the opening of DCR when the law permitting experimentation with DCR passed (Public Health Law from January 2016). Data collection consists of face-to-face interviews (each lasting approximately 20-35 min) administered by a trained interviewer at baseline, 3 months, 6 months and 12 months. Data collection is coordinated by the logistics department of methodology and management (CMG) of ORS PACA - INSERM-IRD UMR1252 (SESSTIM) in Marseilles, under the supervision of the cohort's four PIs (Marc Auriacombe for Bordeaux, Perrine Roux for Marseilles, Marie Jauffret-Roustide for Paris and Laurence Lalanne-Tongio for Strasbourg), and is managed by each site investigator. Participants are compensated for their time with $€ 10$ worth of service vouchers after each of the four interviews.

\section{Participants}

Subjects were eligible if they self-reported injecting illicit drugs except cannabis (heroin, cocaine/crack, amphetamines, ecstasy) and/or prescription drugs (methylphenidate, buprenorphine, benzodiazepines, morphine 
sulfate, oxycodone, methadone) at least once during the previous month. Participants must be over 18 years old and French-speaking. There are no specific exclusion criteria, except if the PWID does not fulfil the inclusion criteria, for example non-French-speaking PWID are excluded. Participants must also provide informed consent to participate in the study. They were recruited mainly in the DCR (in the cities where there is one) and in other harm reduction facilities that currently outreach to PWID likely to attend a DCR if available in each city. This mix of recruitment sites was chosen in order to be able to compare PWID between cities. To avoid duplicate enrollment, the month, year and place of birth are recorded for each participant.

\section{Measures}

The evaluation of DCR is based on the following main outcome: the proportion of participants reporting at least one injection-related HIV-HCV risk practice (sharing of syringes/needles, sharing of other injecting paraphernalia (filter, swab, water, cup, etc.)) in the previous month.

The other variables that will be collected are: socio-demographic characteristics (gender, age, housing, employment, living in a couple, ethnicity, parenthood, social allowances, country of birth); history of drug use (age at first drug use, first injection and related context); current drug and alcohol use (type, frequency, quantity of drugs used, context of drug use, use disorder diagnostic criteria, craving); overdoses and suicide risk; drug use-related HIV-HCV risk practices (injecting, snorting, smoking, sharing and reusing injecting equipment); addiction treatments; DCR attendance; health conditions and access to care and prevention (type and frequency of care, satisfaction with care, HIV, HCV and HBV screening and self-reported HIV and HCV status, education in injection, other HR services); criminality (illegal activities and experience of prison); negative life events (violence, sexual assault, loss of a relative, etc.); psycho-social assessment (anxiety, ADHD, PTSD, etc.); injection initiation (experience and context); cognitive assessments (GONOGO, mnesic test); sexual health (sexual risk practices, contraception); discrimination and life course (parents, childhood).

This interview questionnaire includes the full version or some items from several already validated questionnaires as follows: (1) the Blood-Borne Virus Transmission Risk Assessment ${ }^{28}$ to evaluate the risk practice; (2) a section of the Addiction Severity Index, which is a multi-dimensional questionnaire that measures drug use based on participants' self-report ${ }^{29}{ }^{30} ;(3)$ the Alcohol Use Disorders Identification Test (AUDIT-C) questionnaire to measure alcohol consumption ${ }^{31}$; (4) a set of questions from the PRIMER study to examine injection initiation ${ }^{32}$; (5) three validated questionnaires to measure psychiatric outcomes: the 25-item Wender Utah Rating Scale for attention-deficit/hyperactivity disorder screening, ${ }^{33}$ the Beck Anxiety Inventory to measure anxiety ${ }^{34}$ and the Post-traumatic stress event questionnaire ${ }^{35} 36$; (6) finally, two questionnaires measure participants' cognitive ability: the go-no go task $^{37}$ and the mnesic test. ${ }^{38}$

Table 1 displays the schedule for each assessment.

\section{Sample size}

The main outcome is the comparison of the percentage of PWID reporting at least one injection-related HIV-HCV risk practice during the previous month between the DCR-exposed and DCR-unexposed groups. The sample size needed was calculated according to this main outcome. Many studies from different countries with DCR have shown that between $30 \%^{39} 40$ and $60 \%^{41}$ of users regularly attend them (at least once a week). In the French context, the proportion of PWID reporting at least one injection-related HIV-HCV risk practice varies according to the context and the characteristics of PWID recruited in different studies, from $25 \%$ to $50 \% .{ }^{42}$ We hypothesise $33 \%$ of regular (ie, at least once a week) DCR attending participants will report at least one of these events. Supposing that one-third of participants will regularly attend DCR, with an alpha $=5 \%$ and a power of $80 \%$, we need a total of 131 participants in each group. Given an expected attrition rate of $40 \%$ after 12 months of follow-up, ${ }^{43}$ the sample size is therefore 680 (Paris $=250$, Marseilles $=200$, Bordeaux $=150$, Strasbourg $=80$ ).

\section{Statistical methods}

COSINUS was developed to show the impact of DCR on HIV-HCV risk practices. Longitudinal data analysis will use a mixed logistic model to assess the impact of individual factors (socio-demographic, behavioural and cognitive data) and structural factors, including DCR attendance and exposure to other HR services (access to OMT, social services, education to safer injection, etc.), on the main outcome (reporting at least one injection-related HIV-HCV risk practice during the previous month). Data analysis will be carried out with logistic regression models for qualitative data in two ways: multinomial regression for qualitative data of more than two terms or linear regression for continuous data. In addition, to study the impact of the combined effect of different services (DCR, education about safe injection, other HR services) on the main outcome, we will use mixed-model regression analysis by adjusting for these different structural factors and other covariates. A Cox model-based approach (or duration models) will be used to study the impact of DCR attendance (or other HR services) for a certain event at a certain time (transition from injection to another mode of use, access to care). To take into account bias due to missing data and loss to follow-up, we will perform sensitivity analyses using the Heckman model, which adjusts for this potential source of statistical bias. ${ }^{44}$ Analyses will be performed using several statistical software packages (SPSS V.12.0, Intercooled Stata V.10.0 and SAS; statistical V.10.0). 
Table 1 Summary of data collection at each follow-up visit

\begin{tabular}{|c|c|c|c|c|}
\hline & MO & M3 & M6 & M12 \\
\hline Socio-demographic characteristics & $x$ & $x$ & $x$ & $x$ \\
\hline Socio-economic characteristics & $x$ & $x$ & $x$ & $x$ \\
\hline History of substance use & $x$ & & & \\
\hline Current drug use & $x$ & $x$ & $x$ & $x$ \\
\hline Alcohol and tobacco use & $x$ & $x$ & $x$ & $x$ \\
\hline Overdoses and suicidal risk & $x$ & & $x$ & $x$ \\
\hline Drug use-related HIV-HCV risk practices & $\mathrm{x}$ & $x$ & $\mathrm{x}$ & $\mathrm{x}$ \\
\hline Addiction treatment & $x$ & $\mathrm{x}$ & $x$ & $x$ \\
\hline Health conditions and access to care & $x$ & & $x$ & $x$ \\
\hline Screening for HIV and HCV & $\mathrm{x}$ & & $\mathrm{x}$ & $x$ \\
\hline Criminality & $x$ & $x$ & $x$ & $x$ \\
\hline Prison experience & $x$ & & $x$ & $x$ \\
\hline Negative life events & $x$ & & & $x$ \\
\hline Initiation injection & $x$ & & $x$ & $x$ \\
\hline HR services user satisfaction & $x$ & & $x$ & $\mathrm{x}$ \\
\hline Sexual health & & $x$ & & \\
\hline Other practices at risk of dermal contamination & & $x$ & & \\
\hline DCR attendance and other services & $x$ & $\mathrm{x}$ & $x$ & $\mathrm{x}$ \\
\hline Life course & & $x$ & & \\
\hline Attention Deficit Hyperactivity Disorder & & $x$ & & \\
\hline Anxiety: Beck anxiety inventory & & & $x$ & \\
\hline Post-traumatic stress disorder & & & $x$ & \\
\hline Discrimination & & $\mathrm{x}$ & & \\
\hline GONOGO Task & & $x$ & & $x$ \\
\hline Mnemonic Test & & $x$ & & $x$ \\
\hline
\end{tabular}

$\mathrm{DCR}$, drug consumption rooms; $\mathrm{HCV}$, hepatitis $\mathrm{C}$ virus; $\mathrm{HR}$, harm reduction.

\section{Patient and public involvement}

Although participants did not directly contribute to the design of the study or to the development of the research questions, their needs and preferences were considered throughout the process. Feedback to the participants regarding scientific results, will be organised on each study site.

\section{DISCUSSION}

The COSINUS cohort study is the first in France designed to assess the impact of DCR on HIV-HCV risk practices. It is important to note that DCR in France are seen as an additional tool to existing NEP and OMT programmes, as well as the recently education programme for safer injecting practices. ${ }^{25}$

To date, most of the data published on the effects of DCR are from the Vancouver INSITE research team, ${ }^{45}$ whose work greatly contributed to the preliminary design of our cohort study. However, the French and Vancouver contexts are very different in terms of substances available on the black market, access to OMT, sharing practices, sero-prevalence of HIV and HCV, and harm reduction policy. In France, an estimated 180000 drug users are currently on $\mathrm{OMT}^{46}$ corresponding to an estimated coverage of $80 \%$ in urban areas. ${ }^{725}$ Two-thirds of individuals receiving OMT are treated with buprenorphine. This figure contrasts with other high-level income countries, where methadone is more accessible. ${ }^{47}$ This high coverage of OMT may have played a role in decreasing long-term HCV prevalence over recent years. ${ }^{2-11}$ The decrease in prevalence of HCV has been slower than that seen for HIV. This reflects the situation in other European countries such as the Netherlands and Switzerland. ${ }^{48}$ Overall, despite high coverage of prevention and treatment services, HCV prevalence data suggest that PWID, including those receiving $\mathrm{OMT}^{49}{ }^{4}$ still have a high risk of transmitting HCV. ${ }^{15}{ }^{50}$ DCR can therefore be an addition to existing HCV prevention tools by engaging difficult-torich PWID in OMT and safer injection practices.

Although there are differences between the French and Vancouver contexts in terms of black market substance abuse (see above), and despite some heterogeneity 
across and within the four different metropolitan areas where our study is being conducted, ${ }^{7}$ similarities between the two contexts exist, specifically regarding reduced access to sterile syringes, low socio-economic levels and a high proportion of PWID injecting in public spaces. ${ }^{742}$ COSINUS will help us understand the dynamic of HIV-HCV risk practices at a national level, both in already existing DCR and in sites providing other HR services. In France, incidence of fatal overdoses among PWID is low, making it difficult to reduce it significantly over a 12 month period. This could be related to the national harm reduction policy implemented in the 1990s including access to $\mathrm{OMT}^{6}$ and a high level of OMT coverage. $^{746}$

Many prospective studies have tested, evaluated and validated DCR worldwide and have shown several benefits for public health..$^{20}$ Although public opinion on DCR is mixed and has seen shifting attitudes over time, ${ }^{24} 51$ DCR acceptance by drug users and the drug-using community has been positive to date. ${ }^{52-55}$ Any evaluation of DCR needs to take into account the social environment where DCR are implemented, especially social acceptability by the neighbourhood. ${ }^{56}$ DCR facilitate access to needles and provide safer places for users at high risk both to themselves and to their environment. ${ }^{415758}$ They provide hygienic and safe conditions for intravenous users and staff. They reduce morbidity and mortality associated with overdoses and with HIV and HCV infections, which is not only beneficial to PWID but increases healthcare cost-effectiveness. ${ }^{59}$ They promote access to opioid dependence treatment ${ }^{60}$ and to prevention interventions related to drug injecting practices. ${ }^{6162}$ However, few existing DCR provide education programmes for safer injection ${ }^{63}$ or have a space to inhale drugs. Moreover, data about the combined effect of DCR with other HR services are sparse. The Canadian experience has shown the importance of the evaluation process of such a controversial HR tool. ${ }^{64}{ }^{65}$ More specifically, evidence-based findings from an evaluation process of the DCR 'Insite' helped to advocate against its closure, which was threatened by the federal government. ${ }^{66}$ The COSINUS cohort study will not only study the impact of regularly attendance in DCR on HIV-HCV risk practices in PWID in France, but will also assess the combined effect of DCR together with other HR services (eg, education about safer injection, access to OMT, social activities) on these practices.

Some limitations have to be acknowledged. First, all the data collected were self-reported. Although the use of self-reports may be subject to social desirability bias, studies have shown their reliability in drug-using populations. ${ }^{6768}$ To control any such bias, we used trained interviewers independent of the participating harm reduction facilities. In terms of the diversity of our sample, all the PWID were recruited through easily accessible harm reduction facilities that conduct outreach actions, and which constitute the main contact that the PWID population has with the healthcare system. Another limitation is that, due to cost limitations of our study, we enrolled only French-speaking participants. Further studies are planned to better investigate the impact of DCRs in all the population of PWID including non-French-speaking PWID that represent around $20 \%$ of people who attend DCRs. ${ }^{69}$

In addition to evaluating DCR and other HR services, this cohort will be used for a more global assessment of the needs of the PWID population in terms of access to treatment for addictive disorders. It will also examine the reasons for not seeking treatment, while identifying users who may benefit from it. It will help to provide a greater understanding of users' social conditions, practices, their access to prevention and treatment services and of the role of incarceration and violence in this population often excluded from the healthcare system.

\section{ETHICS AND DISSEMINATION}

All procedures performed were in accordance with the 1964 Helsinki declaration and its later amendments. All participants in the survey gave their informed consent.

The results from this cohort will enable health authorities shape health and harm reduction policies according to PWID needs, as well as improve and create novel harm reduction and therapeutic interventions. All relevant results will be published in peer-reviewed international scientific journals and presented at conferences, nationally and internationally.

\section{Author affiliations \\ ${ }^{1}$ University of Bordeaux, Bordeaux, Aquitaine, France \\ ${ }^{2}$ Addiction Team, SANPSY, CNRS USR 3413, Bordeaux, France \\ ${ }^{3}$ Department of Psychiatry, University of Pennsylvania Center for Studies of Addiction, Philadelphia, Pennsylvania, USA \\ ${ }^{4}$ Pôle Addictologie, $\mathrm{CH}$ Charles Perrens and CHU de Bordeaux, Bordeaux, France ${ }^{5}$ Aix Marseille Univ, INSERM, IRD, SESSTIM, Sciences Economiques \& Sociales de la Santé \& Traitement de l'Information Médicale, Marseille, France \\ ${ }^{6}$ ORS PACA, Observatoire Régional de la Santé Provence-Alpes-Côte d'Azur, Marseille, France \\ ${ }^{7}$ Department of Psychiatry and Addictology, INSERM 1114, University Hospital of Strasbourg, Strasbourg, France \\ ${ }^{8}$ CERMES3 (INSERM U988/UMR CNRS 8211/EHESS/Paris Descartes University), Paris, France \\ ${ }^{9}$ INSERM U1114, Strasbourg, Alsace, France \\ ${ }^{10}$ Department of Psychiatry and Addictology, Hopitaux universitaires de Strasbourg, Strasbourg, France}

Acknowledgements Members of the COSINUS scientific committee: Henri-Jean Aubin and Nerkassen Chau (INSERM U669), Pr Jean-Marie Danion (INSERM U1114 and University Hospital of Strasbourg), Maurice Dematteis (University Hospital of Grenoble), Laurent Karila (INSERM U1000) and Thomas Kerr (British Columbia Centre for Excellence in HIV/AIDS).

Collaborators COSINUS study group: Marc Auriacombe; Gilles Bertoia; Laélia Briand Madrid; Maria Patrizia Carrieri; Isabelle Célérier; Carole Chauvin; JeanMarie Danion; Cécile Denis; Natascia Grelli; Marie Gutowski; Naomi Hamelin; Marie Jauffret-Roustide; Charlotte Kervran; Sébastien Kirchherr; Laurence Lalanne; Mireille Le Breton; Perrine Roux; Antoine Vilotitch.

Contributors Study conception and design: PC, CD, LL, MA, MJ-R, PR. Drafting of manuscript: MA, MJ-R, LL, PR, CK, CD drafted the first version of the manuscript. MA, LL, MJ-R and PR are the COSINUS cohort study PIs. SK, LBM, MG, CK and $\mathrm{CC}$ are the study-site interviewers and contributed to improving the design of the study. All authors significantly contributed to the manuscript and approved the final version. 
Funding This work was supported by the French Government Addiction Agency MILDECA (The inter-ministerial mission to fight against drugs and addictive practices). The funding sponsors had no role in the design of the study and will have no role in data collection, analysis or interpretation of the data. They were not involved in the preparation, review or approval of this manuscript.

\section{Competing interests None declared.}

Patient consent for publication Not required.

Ethics approval This study was approved by the Institutional Review Board (IRB00003888) of the French institute of medical research and health (opinion number: 14-166).

Provenance and peer review Not commissioned; externally peer reviewed.

Open access This is an open access article distributed in accordance with the Creative Commons Attribution Non Commercial (CC BY-NC 4.0) license, which permits others to distribute, remix, adapt, build upon this work non-commercially, and license their derivative works on different terms, provided the original work is properly cited, appropriate credit is given, any changes made indicated, and the use is non-commercial. See: http://creativecommons.org/licenses/by-nc/4.0/.

\section{REFERENCES}

1. Moatti JP, Vlahov D, Feroni I, et al. Multiple access to sterile syringes for injection drug users: vending machines, needle exchange programs and legal pharmacy sales in Marseille, France. Eur Addict Res 2001;7:40-5.

2. Fatseas M, Denis C, Serre F, et al. Change in HIV-HCV risk-taking behavior and seroprevalence among opiate users seeking treatment over an 11-year period and harm reduction policy. AIDS Behav 2012;16:2082-90.

3. Fatseas M, Auriacombe M. Why buprenorphine is so successful in treating opiate addiction in France. Curr Psychiatry Rep 2007:9:358-64.

4. Auriacombe M, Fatséas M, Dubernet J, et al. French field experience with buprenorphine. Am J Addict 2004;13:S17-28.

5. Roux P, Carrieri MP, Cohen J, et al. Retention in opioid substitution treatment: a major predictor of long-term virological success for HIVinfected injection drug users receiving antiretroviral treatment. Clin Infect Dis 2009;49:1433-40.

6. Emmanuelli J, Desenclos JC. Harm reduction interventions, behaviours and associated health outcomes in France, 1996-2003. Addiction 2005;100:1690-700.

7. Weill-Barillet L, Pillonel J, Semaille C, et al. Hepatitis C virus and HIV seroprevalences, sociodemographic characteristics, behaviors and access to syringes among drug users, a comparison of geographical areas in France, ANRS-Coquelicot 2011 survey. Rev Epidemiol Sante Publique 2016;64:301-12.

8. Nelson PK, Mathers BM, Cowie B, et al. Global epidemiology of hepatitis $B$ and hepatitis $C$ in people who inject drugs: results of systematic reviews. Lancet 2011;378:571-83.

9. Murray JM, Law MG, Gao Z, et al. The impact of behavioural changes on the prevalence of human immunodeficiency virus and hepatitis $\mathrm{C}$ among injecting drug users. Int J Epidemiol 2003;32:708-14

10. Page-Shafer K, Hahn JA, Lum PJ. Preventing hepatitis $C$ virus infection in injection drug users: risk reduction is not enough. AIDS 2007;21:1967-9.

11. Denis CM, Fatseas M, Beltran V, et al. Impact of 20 years harm reduction policy on HIV and HCV among opioid users not in treatment. Drug Alcohol Depend 2015;146:e261.

12. Jauffret-Roustide M, Emmanuelli J, Quaglia M, et al. Impact of a harm-reduction policy on HIV and hepatitis $C$ virus transmission among drug users: recent French data-the ANRS-Coquelicot Study. Subst Use Misuse 2006;41:1603-21.

13. Leon L, Kasereka S, Barin F, et al. Age- and time-dependent prevalence and incidence of hepatitis $C$ virus infection in drug users in France, 2004-2011: model-based estimation from two national cross-sectional serosurveys. Epidemiol Infect 2017;145:895-907.

14. de Vos AS, van der Helm JJ, Matser A, et al. Decline in incidence of HIV and hepatitis $C$ virus infection among injecting drug users in Amsterdam; evidence for harm reduction? Addiction 2013;108:1070-81.

15. Cazein F, Pillonel J, Barin F, et al. HIV infection among persons who inject drugs: ending old epidemics and addressing new outbreaks. AIDS 2016;30:1857-8.

16. Kerr T, Wood E, Grafstein E, et al. High rates of primary care and emergency department use among injection drug users in Vancouver. J Public Health 2005;27:62-6.
17. Salmon AM, Dwyer R, Jauncey M, et al. Injecting-related injury and disease among clients of a supervised injecting facility. Drug Alcohol Depend 2009;101:132-6.

18. Dwyer R, Topp L, Maher L, et al. Prevalences and correlates of non-viral injecting-related injuries and diseases in a convenience sample of Australian injecting drug users. Drug Alcohol Depend 2009;100:9-16.

19. Palmateer NE, Hope VD, Roy K, et al. Infections with spore-forming bacteria in persons who inject drugs, 2000-2009. Emerg Infect Dis 2013;19:29-34.

20. Potier C, Laprévote V, Dubois-Arber F, et al. Supervised injection services: what has been demonstrated? A systematic literature review. Drug Alcohol Depend 2014;145:48-68.

21. Wood E, Tyndall MW, Li K, et al. Do supervised injecting facilities attract higher-risk injection drug users? Am J Prev Med 2005;29:126-30.

22. Wood E, Kerr T, Small W, et al. Changes in public order after the opening of a medically supervised safer injecting facility for illicit injection drug users. CMAJ 2004;171:731-4.

23. Marshall BD, Milloy MJ, Wood E, et al. Reduction in overdose mortality after the opening of North America's first medically supervised safer injecting facility: a retrospective population-based study. Lancet 2011;377:1429-37.

24. Jauffret-Roustide M, Pedrono G, Beltzer N. Supervised consumption rooms: the French Paradox. Int J Drug Policy 2013;24:628-30.

25. Roux P, Le Gall JM, Debrus M, et al. Innovative community-based educational face-to-face intervention to reduce HIV, hepatitis $\mathrm{C}$ virus and other blood-borne infectious risks in difficult-to-reach people who inject drugs: results from the ANRS-AERLI intervention study. Addiction 2016;111:94-106

26. Kerr T, Stoltz JA, Tyndall M, et al. Impact of a medically supervised safer injection facility on community drug use patterns: a before and after study. BMJ 2006;332:220-2.

27. Strathdee SA, Patrick DM, Currie SL, et al. Needle exchange is not enough: lessons from the Vancouver injecting drug use study. AIDS 1997;11:F59-65.

28. Fry CL, Lintzeris N. Psychometric properties of the Blood-borne Virus Transmission Risk Assessment Questionnaire (BBV-TRAQ). Addiction 2003;98:171-8.

29. McLellan AT, Kushner H, Metzger D, et al. The fifth edition of the addiction severity index. J Subst Abuse Treat 1992;9:199-213.

30. Denis C, Fatséas M, Beltran V, et al. Usefulness and validity of the modified addiction severity index: a focus on alcohol, drugs, tobacco, and gambling. Subst Abus 2016;37:168-75.

31. Rubinsky AD, Dawson DA, Williams EC, et al. AUDIT-C scores as a scaled marker of mean daily drinking, alcohol use disorder severity, and probability of alcohol dependence in a U.S. general population sample of drinkers. Alcohol Clin Exp Res 2013;37:1380-90.

32. Werb D, Garfein R, Kerr T, et al. A socio-structural approach to preventing injection drug use initiation: rationale for the PRIMER study. Harm Reduct J 2016;13:25.

33. Ward MF, Wender PH, Reimherr FW. The wender utah rating scale: an aid in the retrospective diagnosis of childhood attention deficit hyperactivity disorder. Am J Psychiatry 1993;150:885-90.

34. Beck AT, Epstein N, Brown G, et al. An inventory for measuring clinical anxiety: psychometric properties. J Consult Clin Psychol 1988;56:893-7.

35. Brunet A, St-Hilaire A, Jehel L, et al. Validation of a French version of the impact of event scale-revised. Can J Psychiatry 2003:48:56-61.

36. Horowitz M, Wilner N, Alvarez W. Impact of Event Scale: a measure of subjective stress. Psychosom Med 1979;41:209-18.

37. Dubois B, Slachevsky A, Litvan I, et al. The FAB: a frontal assessment battery at bedside. Neurology 2000;55:1621-6.

38. Dubois B, Touchon J, Portet F, et al. ["The 5 words": a simple and sensitive test for the diagnosis of Alzheimer's disease]. Presse Med 2002;31:1696-9.

39. DeBeck K, Kerr T, Bird L, et al. Injection drug use cessation and use of North America's first medically supervised safer injecting facility. Drug Alcohol Depend 2011;113:172-6.

40. Holtzman D, Barry V, Ouellet LJ, et al. The influence of needle exchange programs on injection risk behaviors and infection with hepatitis $C$ virus among young injection drug users in select cities in the United States, 1994-2004. Prev Med 2009;49:68-73.

41. Bravo MJ, Royuela L, De la Fuente L, et al. Use of supervised injection facilities and injection risk behaviours among young drug injectors. Addiction 2009;104:614-9.

42. Jauffret-Roustide M, Chollet A, Santos A, et al. Theory versus practice, bacteriological efficiency versus personal habits: $A$ bacteriological and user acceptability evaluation of filtering tools for people who inject drugs. Drug Alcohol Rev 2018;37:106-15. 
43. Gindi RM, Rucker MG, Serio-Chapman CE, et al. Utilization patterns and correlates of retention among clients of the needle exchange program in Baltimore, Maryland. Drug Alcohol Depend 2009;103:93-8.

44. Carrieri MP, Rey D, Serraino D, et al. Oral contraception and unprotected sex with occasional partners of women HIV-infected through injection drug use. AIDS Care 2006;18:795-800.

45. Wood E, Kerr T, Lloyd-Smith E, et al. Methodology for evaluating Insite: Canada's first medically supervised safer injection facility for injection drug users. Harm Reduct J 2004;1:9.

46. Brisacier AC. Tableau de bord "Traitements de substitution aux opiacés » Saint-Denis. OFDT, 2015.

47. Carrieri MP, Amass L, Lucas GM, et al. Buprenorphine use: the international experience. Clin Infect Dis 2006;43:S197-215.

48. van den Berg $\mathrm{CH}$, Smit $\mathrm{C}$, Bakker M, et al. Major decline of hepatitis $C$ virus incidence rate over two decades in a cohort of drug users. Eur J Epidemiol 2007;22:183-93.

49. MacArthur GJ, Minozzi S, Martin N, et al. Opiate substitution treatment and HIV transmission in people who inject drugs: systematic review and meta-analysis. BMJ 2012;345:e5945.

50. Jauffret-Roustide M, Le Strat Y, Couturier E, et al. A national crosssectional study among drug-users in France: epidemiology of HCV and highlight on practical and statistical aspects of the design. BMC Infect Dis 2009;9:113.

51. Strike C, Jairam JA, Kolla G, et al. Increasing public support for supervised injection facilities in Ontario, Canada. Addiction 2014;109:946-53.

52. de Jong $\mathrm{W}$, Weber $\mathrm{U}$. The professional acceptance of drug use: a closer look at drug consumption rooms in the Netherlands, Germany and Switzerland. International Journal of Drug Policy 1999;10:99-108.

53. Strike C, Watson TM, Kolla G, et al. Ambivalence about supervised injection facilities among community stakeholders. Harm Reduct $J$ 2015;12:26

54. Salmon AM, Thein $\mathrm{HH}$, Kimber J, et al. Five years on: what are the community perceptions of drug-related public amenity following the establishment of the sydney medically supervised injecting centre? Int J Drug Policy 2007:18:46-53.

55. Kral AH, Wenger L, Carpenter L, et al. Acceptability of a safer injection facility among injection drug users in San Francisco. Drug Alcohol Depend 2010;110:160-3.
56. Jauffret-Roustide M, Cailbault I. Drug consumption rooms: Comparing times, spaces and actors in issues of social acceptability in French public debate. Int J Drug Policy 2018;56:208-17.

57. Kerr T, Tyndall MW, Zhang R, et al. Circumstances of first injection among illicit drug users accessing a medically supervised safer injection facility. Am J Public Health 2007;97:1228-30.

58. Reddon $\mathrm{H}$, Wood $\mathrm{E}$, Tyndall M, et al. Use of North America's first medically supervised safer injecting facility among HIV-positive injection drug users. AIDS Educ Prev 2011;23:412-22.

59. Bayoumi AM, Zaric GS. The cost-effectiveness of Vancouver's supervised injection facility. CMAJ 2008;179:1143-51.

60. Wood E, Tyndall MW, Zhang R, et al. Attendance at supervised injecting facilities and use of detoxification services. N Engl J Med 2006;354:2512-4.

61. Small W, Wood E, Lloyd-Smith E, et al. Accessing care for injectionrelated infections through a medically supervised injecting facility: a qualitative study. Drug Alcohol Depend 2008;98:159-62.

62. Stoltz JA, Wood E, Small W, et al. Changes in injecting practices associated with the use of a medically supervised safer injection facility. J Public Health 2007;29:35-9.

63. Rachlis B, Lloyd-Smith E, Small W, et al. Harmful microinjecting practices among a cohort of injection drug users in vancouver Canada. Subst Use Misuse 2010;45:1351-66.

64. Wood RA, Wood E, Lai C, et al. Nurse-delivered safer injection education among a cohort of injection drug users: evidence from the evaluation of vancouver's supervised injection facility. Int J Drug Policy 2008;19:183-8.

65. Hyshka E, Bubela T, Wild TC. Prospects for scaling-up supervised injection facilities in Canada: the role of evidence in legal and political decision-making. Addiction 2013;108:468-76.

66. Small D. Canada's highest court unchains injection drug users; implications for harm reduction as standard of healthcare. Harm Reduct J 2012;9:34

67. Darke S. Self-report among injecting drug users: a review. Drug Alcohol Depend 1998;51:253-63.

68. Denis C, Fatséas M, Beltran V, et al. Validity of the self-reported drug use section of the addiction severity index and associated factors used under naturalistic conditions. Subst Use Misuse 2012;47:356-63.

69. Jauffret-Roustide M, Serebroskhaya D, Chollet A, et al. Comparison of social profiles practices and situation toward Hepatitis $C$ among Russian-speaking drug users in Paris, France. ANRS-Coquelicot Study 2017:285-90. 